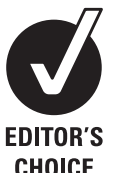

CHOICE

\title{
Comparison of prognostic value of Roper Hall and Dua classification systems in acute ocular burns
}

\author{
Noopur Gupta, ${ }^{1}$ Mani Kalaivani, ${ }^{2}$ Radhika Tandon ${ }^{1}$
}

${ }^{1}$ Cornea and Refractive Surgery Services, Dr Rajendra Prasad Centre for Ophthalmic Sciences, All India Institute of Medical Sciences, New Delhi, India ${ }^{2}$ Department of Biostatistics, All India Institute of Medical Sciences, New Delhi, India

\section{Correspondence to}

Dr Radhika Tandon, Cornea and Refractive Surgery Services, Dr Rajendra Prasad Centre for Ophthalmic Sciences, All India Institute of Medical Sciences, New Delhi, India; radhikatan@yahoo.com

Accepted 23 April 2010 Published Online First 30 August 2010

\section{ABSTRACT}

Aim To compare the predictive outcome of ocular burns using two different prognostic classification systems, that is, Dua and Roper Hall classification.

Patients and methods In a prospective, randomised, controlled clinical trial, the extent of acute ocular burns in 100 patients was graded by Roper Hall and Dua classifications. Patients were randomised in two groups of 50 each to receive conventional medical therapy alone or additional amniotic membrane transplantation (AMT). Moderate burns were graded similarly (grade II and III) under both systems, while severe burns were classified differently and compared further. Baseline parameters (size of epithelial defect, corneal haze, limbal ischaemia, conjunctival involvement and visual acuity) and outcome variables (healing of epithelial defect, corneal clarity, corneal vascularisation, visual outcome and symblepharon) after 1 year were noted and compared.

Results There was no difference in terms of time taken and rate of healing of epithelial defect, but there was a significant difference in extent of corneal vascularisation between grades IV, $V$ and $V I(p<0.05)$. In patients who received AMT in addition to medical therapy, the degree of corneal clarity achieved was significantly better in patients with grade IV burns than either grade $\mathrm{V}(\mathrm{p}=0.045)$ or grade $\mathrm{VI}(\mathrm{p}=0.024)$ burns, and final visual acuity was significantly better in these patients $(p=0.043)$. On comparison of patients with grade IV burns (with and without AMT), the outcome in terms of extent of corneal vascularisation was significantly better $(p=0.0124)$ in patients who received AMT.

Conclusions Dua classification by providing further subclassification of grade IV ocular burns by Roper Hall into three separate grades has a superior prognostic predictive value in severe ocular burns.

\section{INTRODUCTION}

Ocular burns resulting from chemical or thermal injuries lead to extensive and permanent damage to the eye, with visual recovery and healing depending on the extent of initial damage to the ocular tissues. ${ }^{1}$ Various prognostic classification systems based on the extent of ocular damage are available. The Roper Hall classification system ${ }^{2}$ is most commonly applied for classifying acute chemical burns and provides prognostic guidelines based on the degree of corneal haze and extent of limbal ischaemia.

Dua et al have introduced a new, modified classification system ${ }^{3}$ which takes into account the extent of limbal involvement in clock hours and percentage of conjunctival involvement, and subsequently an analogue scale is tabulated for recording the clinical status and grade of ocular surface burn. The advantage of the quasi-analogue scale is that it allows flexibility between 'grades,' especially with regard to conjunctival involvement, as can be seen in real clinical situations. The scores can be recorded on a daily basis following acute burns and can be compared from time to time to predict progression and outcome more accurately.

It is true that the management of ocular surface burns has undergone a dramatic change with the introduction of limbal stem cell transplantation and amniotic membrane grafting. According to Dua et $\mathrm{al}$, one can expect a better prognosis in milder cases of severe burns, all of which have been assigned a single category (grade IV) under the Roper Hall classification system. Hence, Dua et al subclassified patients with grade IV burns into three subclasses on the basis of their series of 67 patients with ocular surface burns. They demonstrated that not all burns with 50-100\% limbal involvement could have the same prognostic outcome and that the prognosis of patients with $100 \%$ limbal involvement is much worse than patients with just over $50 \%$ limbal involvement and ideally should not be grouped together. ${ }^{3}$

Various authors are of the view that there are lacunae in the Roper Hall classification system, but the Dua classification has not yet been validated in randomised, prospective clinical trials to provide substantial evidence that it is better than Roper Hall classification for improving patient management and predicting outcome in ocular burns. ${ }^{4} \mathrm{We}$ undertook a prospective, clinical study to evaluate the role of amniotic membrane transplantation (AMT) as an adjunct to standard medical therapy in acute ocular burns. ${ }^{5}$ The burn injuries were classified using Roper Hall and Dua classification systems. We analysed the data gathered through this study with a view to comparing the prognostic value of the two classification systems.

\section{PATIENTS AND METHODS}

Patients presenting with acute chemical or thermal ocular burns at Dr Rajendra Prasad Centre for Ophthalmic Sciences, All India Institute of Medical Sciences (AIIMS) were included. Approval for conducting the study was obtained from the Ethics Committee, AIIMS, New Delhi, India.

A detailed ophthalmic workup including history was performed. Visual acuity was recorded using Snellen charts and converted to $\log M A R$ equivalents using a conversion table. Slit-lamp biomicroscopy was used to note the extent of conjunctival involvement $(\%),{ }^{3}$ limbal involvement in clock hours and presence of symblepharon. Cornea was examined for extent of haze, grade of clarity, size 
of epithelial defect and corneal vascularisation. Corneal clarity was given a value from 0 to 4 (table 1). The size of the epithelial defect was measured on the slit lamp aided by fluorescein staining and the area calculated by product of the dimensions of the largest diameter and the diameter perpendicular to it.

The burns were classified using Roper Hall and Dua classification systems.

Fifty patients with moderate burns (grades II and III by Roper Hall and Dua classification) and 50 patients with severe burns (grade IV by Roper Hall classification and grades IV, V and VI by Dua classification) were included. After obtaining informed consent, the patients were randomised by stratified randomisation using a treatment assignment list prepared with the help of a table of random numbers. Serial numbers were given to the cases, and concealed randomisation using sealed envelopes was followed to decide whether a subject would either receive AMT combined with medical therapy or conventional medical therapy alone. Patients with bilateral involvement were randomised as individuals, and the right eye was randomised.

\section{Medical treatment}

All patients included in the study were started on medical therapy, which included topical prednisolone acetate $(1 \%)$ every $6 \mathrm{~h}$; ofloxacin $(0.3 \%)$ every $6 \mathrm{~h}$; sodium ascorbate (10\%) every $4 \mathrm{~h}$, sodium citrate $(10 \%)$ every $4 \mathrm{~h}$ and preservative-free tear substitutes every $2 \mathrm{~h}$; homatropine (2\%) twice daily and oral vitamin C (500 mg) every $6 \mathrm{~h}$ for 2 to 4 weeks. Antiglaucoma therapy including timolol maleate $0.5 \%$ drops and/or oral acetazolamide was prescribed if required.

Patients in the study group received medical therapy in addition to amniotic membrane transplantation, while the control group received medical therapy alone.

\section{Analysis strategy}

Data collected were analysed to evaluate the two classification systems in relation to the final outcome to assess their predictive value. The differences in baseline variables were noted in 50 patients with severe burns. As the mode of intervention may have influenced the final outcome, the analysis of the patients treated with medical therapy and patients treated with AMT in addition was done separately. Parameters evaluated to assess the predictive value in determining the final outcome included time taken and rate of healing of the damaged corneal epithelium, corneal clarity, extent of corneal vascularisation (implying limbal stem cell deficiency), visual outcome and presence of symblepharon. The final outcome was analysed in patients with severe burns to note whether there was any significant difference between grades IV, V and VI by Dua classification, which were classified into a single grade (IV) by Roper Hall.

\section{Statistical analysis}

Data analysis was carried out using STATA 9.0. Data were described as number (\%) or median (range). Continuous response variables were compared between the groups using Kruskal-Wallis test, since the data were non-normal. Categor-

Table 1 Grading of corneal clarity on the basis of corneal haze

\begin{tabular}{ll}
\hline Grade & Ocular details \\
\hline 0 & No corneal haze \\
1 & Iris details visible \\
2 & Pupillary margin visible, iris details not visible \\
3 & Pupillary margin not visible \\
4 & Cornea totally opaque \\
\hline
\end{tabular}

ical response variable were analysed between the groups using $\chi^{2}$ test/Fisher exact test as appropriate. Any $p$ value less than 0.05 was considered statistically significant.

\section{RESULTS}

Roper Hall classified acute ocular burns into four grades ${ }^{2}$ and assigned a single grade (IV) to all patients with more than $50 \%$ limbal ischaemia. Dua et al proposed a modification of this classification system by dividing all cases of acute ocular burns into six grades, keeping grade II and III exactly similar (moderate burns) to the original classification. The only difference in the new classification was grading of patients with more than $50 \%$ limbal ischaemia (subdivided into grade IV, V and VI) and the incorporation of conjunctival involvement as an additional parameter.

\section{Patients}

One hundred eyes of 100 patients with acute ocular burns were included. The average age of the patients was 22 (4-52) years, with 87 males and 13 females who participated in the study. Out of a total of 50 patients with moderate burns, 24 were grade II, and 26 were grade III. There were 50 patients with severe burns (grade IV by Roper Hall classification) who were subdivided further into three groups by Dua classification system and comprised 12, 16 and 22 patients respectively (table 2).

The differences in baseline variables under the two classification systems in a total of 50 patients with severe burns are summarised in table 3 . The average follow-up of patients with acute ocular burns was $13.2 \pm 3.8$ months.

\section{Severe burns treated with standard medical therapy}

The average time taken for complete healing of the epithelial defect in group IV by the Dua system (31 days) was less than in group VI (60 days), implying faster healing rate in patients with $50-75 \%$ limbal involvement as compared with patients with $100 \%$ limbal involvement, though the results were not statistically significant $(\mathrm{p}=0.082)$.

The extent of limbal stem cell deficiency was adjudged by the degree of corneal vascularisation at the final visit. There was a statistically significant difference in the extent of corneal vascularisation $(\mathrm{p}=0.029)$ in grade IV and grade VI ocular burn by Dua classification, thereby illustrating the importance of subclassifying grade IV Roper Hall classification into three separate grades (ie, IV, V and VI) by Dua et al (table 4).

\section{Severe burns treated with AMT and standard medical therapy} Degree of corneal clarity achieved in patients with grade IV burns was significantly better when compared with patients with either grade $\mathrm{V}(\mathrm{p}=0.045)$ or grade VI $(\mathrm{p}=0.024)$ ocular burn. In cases with $50-75 \%$ limbal involvement (grade IV burn by Dua classification), the final visual acuity was significantly better than patients with total limbal stem cell damage (grade VI burn). Degree of corneal vascularisation was significantly

Table 2 Distribution of patients by Roper Hall and Dua classification

\begin{tabular}{llllllc}
\hline \multirow{2}{*}{ Roper Hall } & \multicolumn{2}{l}{ Dua } & & & & \\
\cline { 2 - 6 } & II & III & IV & V & VI & Total \\
\hline II & 24 & - & - & - & - & 24 \\
III & - & 26 & - & - & - & 26 \\
IV & - & - & 12 & 16 & 22 & 50 \\
Total & 24 & 26 & 12 & 16 & 22 & 100 \\
\hline
\end{tabular}


Table 3 Comparison of baseline variables with the Roper Hall and Dua classification systems

\begin{tabular}{|c|c|c|c|c|}
\hline & \multirow{2}{*}{$\begin{array}{l}\text { Baseline variable } \\
\text { median (range) }\end{array}$} & \multicolumn{3}{|l|}{ p Value } \\
\hline & & IV and V & V and VI & IV and $\mathrm{V}$ \\
\hline \multicolumn{5}{|c|}{ Size of epithelial defect $\left(\mathrm{mm}^{2}\right)$} \\
\hline Roper Hall IV & $144(16-144)$ & 0.7049 & 0.0008 & 0.0003 \\
\hline Dua IV & $122(16-144)$ & & & \\
\hline Dua V & $144(16-144)$ & & & \\
\hline Dua VI & 144 & & & \\
\hline \multicolumn{5}{|c|}{ Extent of corneal haze (\%) } \\
\hline Roper Hall IV & $80(20-100)$ & 0.2676 & 0.0005 & 0.0758 \\
\hline Dua IV & $60(50-100)$ & & & \\
\hline Dua V & $55(20-100)$ & & & \\
\hline Dua VI & $100(50-100)$ & & & \\
\hline \multicolumn{5}{|c|}{ Grade of corneal clarity } \\
\hline Roper Hall IV & $3(0-4)$ & 0.4831 & 0.0185 & 0.0050 \\
\hline Dua IV & $2.5(0-4)$ & & & \\
\hline Dua V & $3(2-4)$ & & & \\
\hline Dua VI & $4(1-4)$ & & & \\
\hline \multicolumn{5}{|c|}{ Limbal ischaemia (clock hours) } \\
\hline Roper Hall IV & $10(7-12)$ & 0.0000 & 0.0000 & 0.0000 \\
\hline Dua IV & $8(7-8)$ & & & \\
\hline Dua V & $9(9-10)$ & & & \\
\hline Dua VI & 12 & & & \\
\hline \multicolumn{5}{|c|}{ Conjunctival involvement (\%) } \\
\hline Roper Hall IV & NA & 0.0105 & 0.1826 & 0.0002 \\
\hline Dua IV & $0(0-50)$ & & & \\
\hline Dua V & $50(0-100)$ & & & \\
\hline Dua VI & $50(0-100)$ & & & \\
\hline \multicolumn{5}{|c|}{ Decimal visual acuity } \\
\hline Roper Hall IV & $0.0055(0.0001-0.67)$ & 0.4811 & 0.3196 & 0.0851 \\
\hline Dua IV & $0.013(0.0001-0.67)$ & & & \\
\hline Dua V & $0.01(0.0001-0.5)$ & & & \\
\hline Dua VI & $0.001(0.0001-0.5)$ & & & \\
\hline \multicolumn{5}{|c|}{ LogMAR visual acuity } \\
\hline Roper Hall IV & $2.5(0.2-4)$ & 0.5108 & 0.3196 & 0.0956 \\
\hline Dua IV & $1.9(0.2-4)$ & & & \\
\hline Dua V & $2(0.3-4)$ & & & \\
\hline Dua VI & $3(0.3-4)$ & & & \\
\hline
\end{tabular}

more extensive in patients with either grade $\mathrm{V}(\mathrm{p}=0.022)$ or grade VI burn $(p=0.005)$ as compared with patients with grade IV burns by the Dua classification (table 5).

\section{Conjunctival involvement}

The conjunctival involvement ranged from 0 to $50 \%$ in patients with moderate burns, the average being $20 \%$. In patients with severe burns, the conjunctival involvement ranged from 0 to $100 \%$, the average being $25 \%$. The relevance of inclusion of conjunctival involvement in the prognostic classification of Dua et al was studied and statistically analysed. There was a significant difference in outcome in terms of corneal vascularisation between patients with $0-25 \%$ conjunctival involvement and patients with $100 \%$ conjunctival involvement $(p=0.0008)$. Moreover, in grade 5 ocular burn $(75-99.9 \%$ conjunctival involvement), the outcome in terms of corneal vascularisation in patients with $0-25 \%(n=7)$ conjunctival involvement was significantly different from patients with $26-50 \% \quad(n=8)$
Table 4 Difference in outcome in patients with various grades of severe burns treated with standard medical management

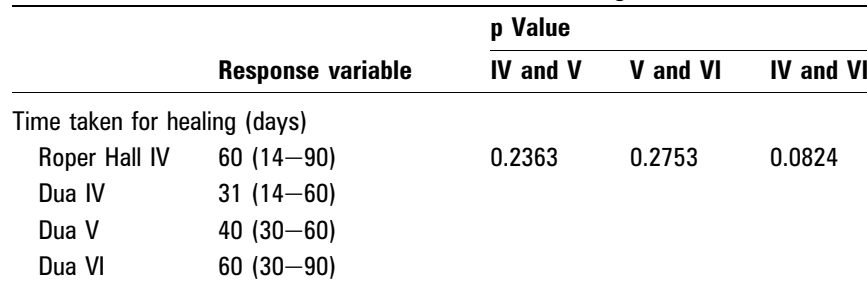

Epithelial healing rate $\left(\mathrm{mm}^{2} /\right.$ day)

$\begin{array}{lllll}\text { Roper Hall IV } & 2.4(0.27-4.8) & 0.6156 & 0.5784 & 0.3175 \\ \text { Dua IV } & 1.87(1.1-4.8) & & & \\ \text { Dua V } & 3.4(0.27-4.8) & & & \\ \text { Dua VI } & 2.4(1.6-4.8) & & & \end{array}$

Extent of corneal haze (\%)

$\begin{array}{lllll}\text { Roper Hall IV } & 75(0-100) & 0.8128 & 0.9654 & 0.4461 \\ \text { Dua IV } & 55(50-100) & & & \\ \text { Dua V } & 50(50-100) & & & \end{array}$

Grade of corneal clarity

$\begin{array}{lllll}\text { Roper Hall IV } & 3(0-4) & 0.6017 & 0.1386 & 0.4982 \\ \text { Dua IV } & 2.5(1-4) & & \end{array}$

Dua V $2(1-3)$

Dua VI $\quad 3(0-4)$

$\begin{array}{lllll}\text { Corneal vascularisation (quadrants involved) } & & & \\ \text { Roper Hall IV } & 4(1-4) & 0.2118 & 0.5142 & 0.0290 \\ \text { Dua IV } & 2.5(1-4) & & & \\ \text { Dua V } & 4(1-4) & & & \\ \text { Dua VI } & 4(2-4) & & & \end{array}$

Decimal Visual acuity

$\begin{array}{lllll}\text { Roper Hall IV } & 0.01(0.0001-0.67) & 1.0000 & 0.1677 & 0.2971 \\ \text { Dua IV } & 0.075(0.0001-0.67) & & & \\ \text { Dua V } & 0.01(0.01-0.5) & & \\ \text { Dua VI } & 0.0055(0.0001-0.67) & & \end{array}$

LogMAR visual acuity

\begin{tabular}{lllll} 
Roper Hall IV & $2(0.2-4)$ & 1.0000 & 0.1677 & 0.2971 \\
Dua IV & $1.15(0.2-4)$ & & & \\
Dua V & $2(0.3-2)$ & & \\
Dua VI & $2.5(0.2-4)$ & & \\
\hline
\end{tabular}

conjunctival involvement ( $\mathrm{p}=0.05)$, signifying the importance of conjunctival involvement. Patients with less than one-fourth conjunctival involvement had a better prognosis than patients with more than $25 \%$ loss of conjunctival tissue, even when the extent of limbal damage was similar.

The correlation of conjunctival involvement at presentation with development of symblepharon at the final visit was also studied. In patients who received standard medical therapy alone, the degree of conjunctival involvement was significantly more in patients with symblepharon formation at the final visit $(p=0.016)$. Patients who were treated with AMT along with conventional therapy also demonstrated that the degree of conjunctival involvement significantly affected the final symblepharon formation $(p=0.013)$.

\section{Role of current management strategies}

The role of interventional strategies like AMT in deciding the outcome in various grades of Dua classification was also studied. 
Table 5 Difference in outcome in patients with various grades of severe burns treated with amniotic membrane transplantation along with standard medical therapy

\begin{tabular}{|c|c|c|c|c|}
\hline & \multirow[b]{2}{*}{ Response variable } & \multicolumn{3}{|c|}{$\begin{array}{l}\text { p Value for difference between } 2 \\
\text { grades }\end{array}$} \\
\hline & & IV and V & $\mathrm{V}$ and $\mathrm{VI}$ & IV and VI \\
\hline \multicolumn{5}{|c|}{ Time taken for healing (days) } \\
\hline Roper Hall IV & $30(12-90)$ & 0.9512 & 0.5925 & 0.9537 \\
\hline Dua IV & $32.5(12-90)$ & & & \\
\hline Dua V & $35(30-70)$ & & & \\
\hline Dua Vl & $30(30-90)$ & & & \\
\hline \multicolumn{5}{|c|}{ Epithelial healing rate $\left(\mathrm{mm}^{2} /\right.$ day $)$} \\
\hline Roper Hall IV & $2.8(1-4.8)$ & 0.4763 & 0.1734 & 0.0884 \\
\hline Dua IV & $1.9(1.2-4.8)$ & & & \\
\hline Dua V & $2.4(1-4.8)$ & & & \\
\hline Dua VI & $4.8(1.6-4.8)$ & & & \\
\hline \multicolumn{5}{|c|}{ Extent of corneal haze (\%) } \\
\hline Roper Hall IV & $80(50-100)$ & 0.2157 & 0.0133 & 0.3625 \\
\hline Dua IV & $85(50-100)$ & & & \\
\hline Dua V & $50(50-100)$ & & & \\
\hline Dua VI & $100(60-100)$ & & & \\
\hline \multicolumn{5}{|c|}{ Grade of corneal clarity } \\
\hline Roper Hall IV & $2(0-4)$ & 0.0446 & 0.6313 & 0.0242 \\
\hline Dua IV & $1(0-3)$ & & & \\
\hline Dua V & $2(1-4)$ & & & \\
\hline Dua VI & $3(1-4)$ & & & \\
\hline \multicolumn{5}{|c|}{ Corneal vascularisation (quadrants involved) } \\
\hline Roper Hall IV & $4(1-4)$ & 0.0223 & 0.2738 & 0.0056 \\
\hline Dua IV & $2(1-4)$ & & & \\
\hline Dua V & $4(2-4)$ & & & \\
\hline Dua VI & $4(2-4)$ & & & \\
\hline \multicolumn{5}{|c|}{ Decimal visual acuity } \\
\hline Roper Hall IV & $0.016(0.0001-1)$ & 0.3143 & 0.1535 & 0.0429 \\
\hline Dua IV & $0.215(0.001-1)$ & & & \\
\hline Dua V & $0.08(0.0001-0.5)$ & & & \\
\hline Dua VI & $0.01(0.0001-0.25)$ & & & \\
\hline \multicolumn{5}{|c|}{ LogMAR visual acuity } \\
\hline Roper Hall IV & $1.8(0-4)$ & 0.3143 & 0.1535 & 0.0429 \\
\hline Dua IV & $0.75(0-3)$ & & & \\
\hline Dua V & $1.1(0.3-4)$ & & & \\
\hline Dua VI & $2(0.6-4)$ & & & \\
\hline
\end{tabular}

The outcome in terms of extent of corneal vascularisation in ocular surface burns after AMT was significantly better $(p=0.0124)$ in grade IV burns. On the contrary, patients with grade 6 burns demonstrated no significant improvement in outcome with AMT $(p=0.9181)$. Extensive symblepharon formation was seen in grade VI burns (15) as against grade IV burns $(8)$ at the final visit $(p=0.0000)$. Moreover, AMT was efficacious in preventing symblepharon formation in group IV but not in group VI $(p=0.0082)$.

\section{DISCUSSION}

Various prognostic classification schemes for chemical injuries exist and are used to grade ocular burns for identifying appropriate treatment and forecasting outcome..$^{2-4}$ Roper Hall classified all patients with $50-100 \%$ limbal ischaemia into a single group (grade IV) and predicted a similar outcome in all such cases. ${ }^{2}$ Dua et al stressed that the prognosis and outcome of patients with $50-100 \%$ limbal ischaemia cannot be similar, and they should be classified into different grades to facilitate proper management of such cases. ${ }^{3}{ }^{6}$ We therefore studied the difference in outcome between grade IV, V and VI burns by Dua classification and whether the Dua classification offers a superior predictive value in patients with acute ocular burns.

We report a significant difference in outcome in patients who were classified in the same group by Roper Hall. In patients with severe burns who were treated with medical therapy alone, the extent of corneal vascularisation was significantly different between grade IV and grade VI ocular burn $(p=0.029)$ by Dua classification. Likewise, in patients who received AMT, the degree of corneal vascularisation was significantly more extensive in patients with either grade $\mathrm{V}(\mathrm{p}=0.022)$ or grade VI burn $(p=0.005)$ as compared with grade IV burns, denoting the relevance of subclassifying grade IV Roper Hall classification into three groups. Corneal vascularisation, a marker of limbal stem cell deficiency, is an important outcome variable in all cases of acute chemical burns. The extent of limbal stromal inflammation and conjunctivalisation of the cornea decides the ultimate outcome in all cases of acute ocular burns.

In our study, the degree of corneal clarity achieved in patients with grade IV burns was significantly better than grade $\mathrm{V}$ $(p=0.045)$ or grade VI $(p=0.024)$ ocular burn. In cases with $50-75 \%$ limbal involvement (grade IV burn by Dua classification), the final visual acuity was better than patients with total limbal stem cell damage (grade VI burn). Hence, these cases, which were grouped together by Roper Hall, were shown to have a varied final outcome, thus validating the Dua classification.

In the Dua classification system, conjunctival involvement is taken as an important parameter for assessing severity. The presence of any surviving conjunctival epithelium in a case of total ocular burn with $100 \%$ limbal ischaemia and total corneal epithelial defect is a favourable prognostic factor. In our study, symblepharon formation correlated positively with the extent of conjunctival involvement, regardless of the therapy instituted. The prognosis was significantly better in patients with $25 \%$ conjunctival damage as compared with patients with $100 \%$ loss of conjunctival tissue. In patients with the same degree of burn (grade 5: 50-75\% limbal involvement) under Dua classification, the outcome was better in patients with more surviving conjunctival epithelium.

Ocular surface reconstruction procedures are being extensively used in patients of ocular burns for rehabilitation and improving visual outcome in such cases. ${ }^{7}$ With the advent of LSCT $^{8}$ and amniotic membrane grafting, ${ }^{9-11}$ the prognosis of less severe grades of burns is enhanced. In our study, AMT was beneficial in patients with $50-75 \%$ limbal involvement and resulted in improved outcome in grade IV burns by Dua classification.

The prognosis of Dua grade VI burns is poor, and the use of AMT for grade VI burns is limited. This may be due to the presence of chronic ocular surface inflammation in these cases, which could affect the success of AMT and limbal transplantation procedures. It is not enough to simply note the healing of the epithelial defect, but to ascertain the nature and morphology of the covering epithelium. Impression cytology is a good method to monitor the inflammatory status ${ }^{12}$ and also to assess whether the covering epithelium is corneal or conjunctival in origin. Hence, classification schemes could be improved further to incorporate the inflammatory status to better prognosticate outcome in these cases.

The International Life Sciences Institute (ILSI) in the USA has reported their classification scheme for chemical injuries ${ }^{13}$ with 
the additional purpose of collecting human eye injury data. The new scheme classifies chemical eye injury into five categories based on clinical signs, symptoms and expected outcomes. It is similar to the Dua classification in assigning grades according to the limbal involvement and does not assign a single grade to all patients with more than $50 \%$ limbal damage.

Harun et al proposed that in the absence of good evidence for reclassifying ocular surface injuries, ${ }^{4}$ Roper Hall classification should not be replaced by Dua classification. Our study provides the evidence that has long been needed and proves that Dua classification provides better prognostic guidelines in cases of ocular surface burns and has a better predictive value than the Roper Hall classification. Dua classification is simple and easy to use, and has a better predictability and accuracy than the Roper Hall classification for management and prognostication of ocular surface burns. We hope that the wider application of Dua classification among clinicians will lead to uniform comparison of published outcomes of new management strategies as well as improve patient management and outcome in cases of acute ocular burns.

Competing interests None.

Patient consent Obtained.

Ethics approval Ethics approval was provided by the Ethics Commitee AllMS.

Provenance and peer review Not commissioned; externally peer reviewed.

\section{REFERENCES}

1. Ballen PH. Treatment of chemical burns of the eye. Eye Ear Nose Throat Mon 1964:43:57-8.

2. Roper-Hall MJ. Thermal and chemical burns. Trans Ophthalmol Soc UK 1965;85:631-40.

3. Dua HS, King AJ, Joseph A. New classification of ocular surface burns. Br J Ophthalmol 2001;85:1379-83.

4. Harun S, Srinivasan S, Hollingworth $\mathrm{K}$, et al. Modification of classification of ocular chemical injuries. Br J Ophthalmol 2004;88:1353-5.

5. Tandon R, Gupta N, Kalaivani M, et al. Amniotic membrane transplantation as an adjunct to medical therapy in acute ocular burns. Br J Ophthalmol 2011;95:199-204.

6. Joseph A, Dua HS, King AJ. Failure of amniotic membrane transplantation in the treatment of acute ocular burns. Br J Ophthalmol 2001;85:1065-9.

7. Meller D, Pires RT, Mack RJ, et al. Amniotic membrane transplantation for acute chemical or thermal burns. Ophthalmology 2000;107:980-9.

8. Nakamura T, Inatomi T, Sotozono C, et al. Successful primary culture and autologous transplantation of corneal limbal epithelial cells from minimal biopsy for unilateral severe ocular surface disease. Acta Ophthalmol Scand 2004;82:468-71

9. Kobayashi A, Shirao Y, Yoshita T. Temporary amniotic membrane patching for acute chemical burns. Eye 2003:17:149-58.

10. Kheirkhah A, Johnson DA, Paranjpe DR, et al. Temporary sutureless amniotic membrane patch for acute alkaline burns. Arch Ophthalmol 2008:126:1059-66.

11. Shimazaki J, Yang H, Tsubota K. Amniotic membrane transplantation for ocular surface reconstruction in patients with chemical and thermal burns. Ophthalmology 1997:104:2068-76.

12. Gicquel JJ, Navarre R, Langman ME, et al. The use of impression cytology in the follow-up of severe ocular burns. Br J Ophthalmol 2007;91:1160-4.

13. Daniel M, Bagley A, Phillip L, et al. Proposed new classification scheme for chemical injury to the human eye. Regul Toxicol Pharmacol 2006;45:206-13. 